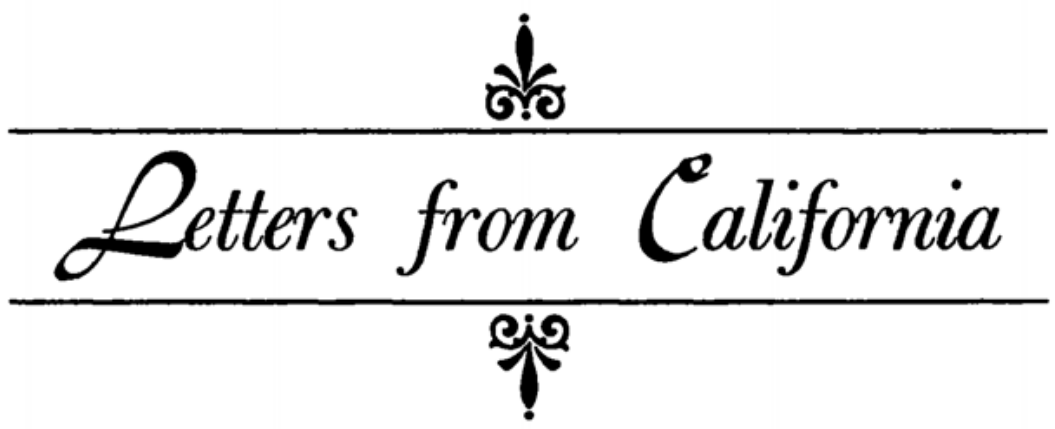






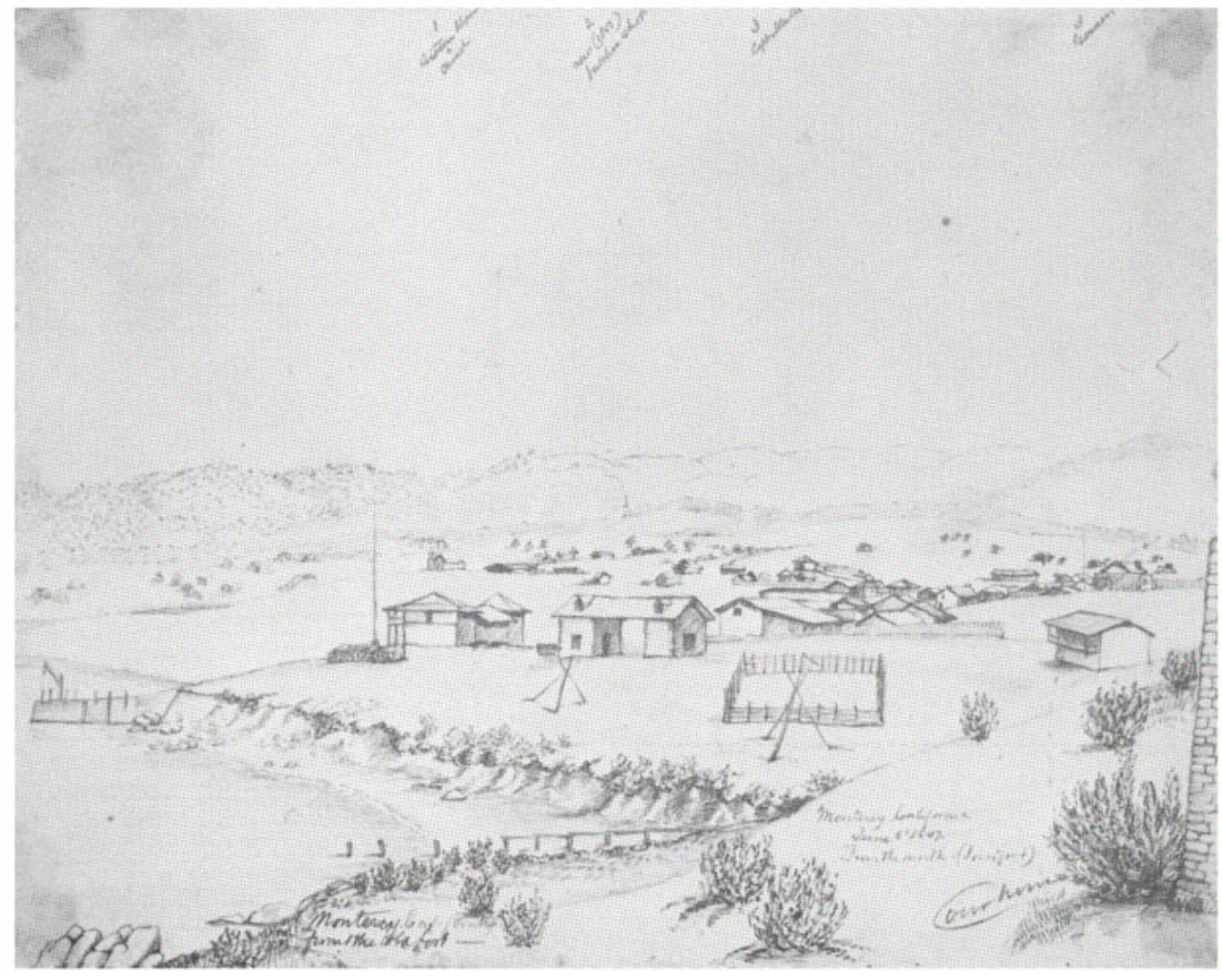

Monterey, June 5, 1847: A General View from Jones' Fort by William R. Hutton. Garner's balconied house is at the far right; the chute for carrying drinking water to the ships is seen in the center foreground; Larkin's wharf with hoist is at the far left. The pole tripods were probably for cutting up beeve for the new butchershop, which is the odd double building near the Customhouse. 


\section{William Robert Garner}
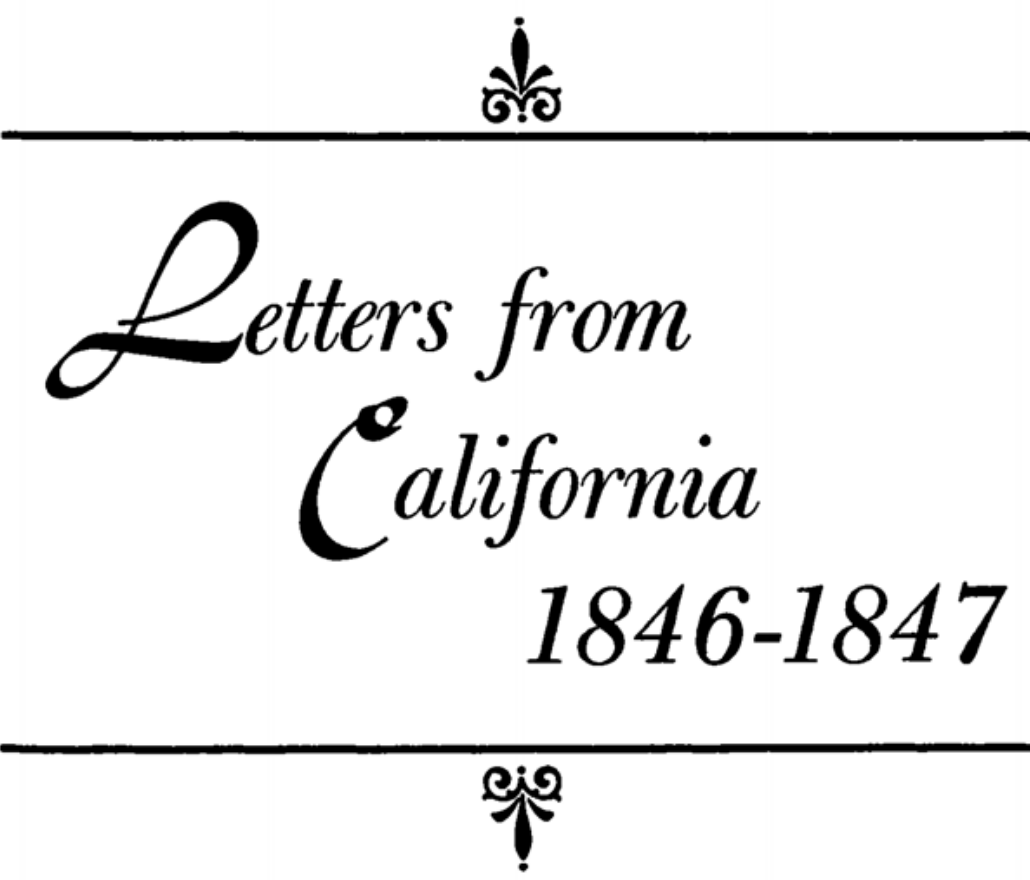

EDITED, WITH A SKETCH OF THE LIFE AND TIMES OF THEIR AUTHOR, BY DONALD MUNRO GRAIG

University of California Press Berkeley, Los Angeles, and London 1970 
University of California Press Berkeley and Los Angeles, California University of California Press, Ltd. London, England Copyright (C) 1970 , by The Regents of the University of California ISBN: 0-520-01565-7

Library of Congress Catalog Card Number: 71-124736

Printed in the United States of America

Designed by Dave Comstock 